\title{
Climate Change and the Jamestown S'Klallam Tribe: A Customized Approach to Climate Vulnerability and Adaptation Planning
}

\author{
ALEXANDER “SASCHA” PETERSEN ${ }^{1 *}$, HANSI HALS ${ }^{2}$, BYRON ROT $^{2}$, \\ JACOB BELL ${ }^{1}$, IAN MILLER ${ }^{3}$, JAMES PARKS ${ }^{1,4}$, MISSY STULTS ${ }^{1,5}$ \\ Volume 2, Fall 2014 \\ http://dx.doi.org/10.3998/mjs.12333712.0002.003 \\ ${ }^{1}$ Adaptation International, 1102 Fieldcrest Drive, Austin, TX 78704 \\ 2Jamestown S'Klallam Tribe, 1033 Old Blyn Highway, Sequim, WA 98382 \\ ${ }^{3}$ Washington Sea Grant, 3716 Brooklyn Ave NE, Seattle, WA 98105 \\ ${ }^{4}$ City of Berkeley, 1947 Center Street, Berkeley, CA 94704 \\ 5University of Michigan, School of Natural Resources \& Environment, \\ 440 Church Street, Ann Arbor, Ml 48109 \\ *Corresponding author: Alexander "Sascha" Petersen, \\ sascha@adaptationinternational.com
}

\section{ABSTRACT}

There are many challenges to achieving local-level climate resilience, including limited access to detailed climate projections, limited inclusion of traditional ecological knowledge, and difficulty in establishing effective climate change impact dialogue across sectors and the community at large. In 2013, the Jamestown S'Klallam Tribe initiated a project to identify and begin addressing the risk the community faces from climate change. Using a combination of structured sector-specific meetings and a two-day workshop, the project used a collaborative approach to identify vulnerabilities, select and prioritize key areas of concern, and develop adaptation strategies to reduce vulnerability and increase resilience. This approach allowed community members to focus their limited time and resources on the areas and assets that are most important to them. The approach also increased understanding of how climate change will impact the community and the strategies available to reduce 
vulnerability to those impacts. Preparing for the impacts of climate change, like addressing other sustainability issues, is not an outcome but a process. The approach taken by the Jamestown S'Klallam Tribe lays a solid foundation for that process and positions the Tribe to build climate resilience, protect and maintain important resources, ensure continued economic growth, and promote long-term community and cultural vitality.

\section{Introduction}

The Jamestown S'Klallam Tribe lives in and remains connected to the resource-rich ecosystems of the Northern Olympic Peninsula in Washington State (Figure 1).

Tribal citizens have inhabited the region for more than 10,000 years (Allen 2014; Waters et al. 2011) and have successfully navigated a variety of climate and social-ecological changes during that time. Now, as in many communities in the United States and the world, ongoing climate change introduces unique challenges that require explicit consideration and planning (Bierbaum et al. 2013; Cordalis and Suagee 2008; International Institute for Indigenous Resource Management 2010; Intertribal Climate Change Working Group 2009). As Ron Allen, Jamestown S'Klallam Tribal Chairman, noted: "In my opinion, to ensure continued economic growth, promote long-term community vitality and protect sensitive resources and assets, it is essential that we incorporate climate change into our planning efforts and operations" (Allen 2014).

Challenges unique to local-level climate change response include limited access to high-resolution climate change projections, limited inclusion of traditional ecological knowledge in climate impact analysis and vulnerability assessments, limited access to funding required to implement many needed adaptation actions, and difficulty in establishing effective dialogue on the impacts of climate change across sectors and the community at large (Bierbaum et al. 2013; Carmin, Nadkarni, and Rhie 2012; Ford et al. 2010; Measham et al. 2011; Moser and Ekstrom 2010; Muntaner et al. 2012; National Research Council 2010a). However, American Indian and Alaska Native tribal communities who have innovated and adapted to historical and ongoing environmental change have expertise (often termed traditional ecological knowledge) and offer a wealth of methods to overcome these challenges. A collaborative approach that synthesizes scientific understanding of climate change with locally understood impact pathways is increasingly proving to be an effective 


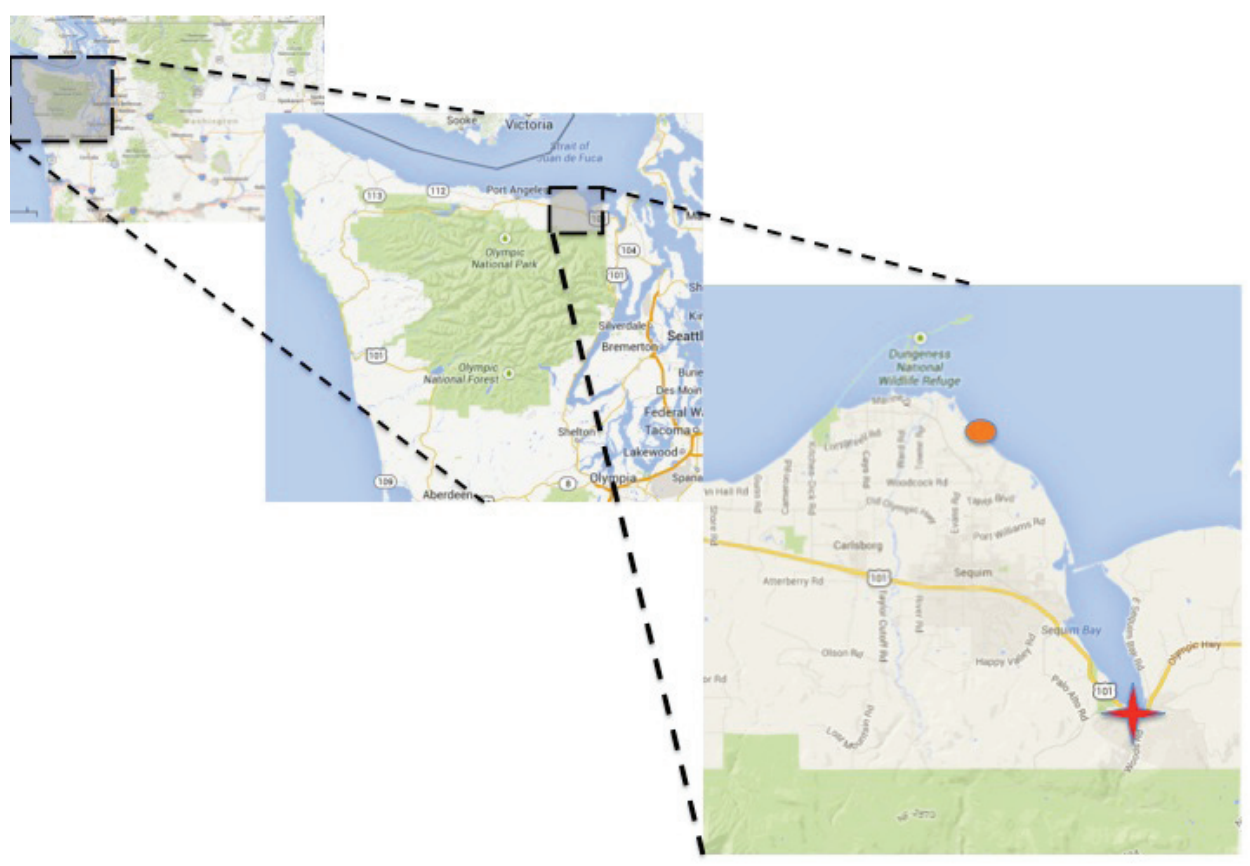

Figure 1. Map of the project area. From left to right are images of Washington State, the Olympic Peninsula, and the Jamestown S'Klallam Community. The orange oval is the Jamestown Beach area, and the red star is the main tribal campus area in Blyn, Washington. Images from Google Maps.

local adaptation planning process (Lamb and Davis 2011; Mariella et al. 2009; National Research Council 2010a; Brubaker et al. 2011).

In 2013, the Jamestown S'Klallam Tribe began a project to identify and address the risks the community faces from climate change. In collaboration with Adaptation International and Washington Sea Grant, the team completed a comprehensive assessment of community vulnerability to climate change and developed and prioritized adaptation actions. This approach successfully diverged from the common climate assessment approach, where available scientific climate modeling drives the selection of vulnerability variables (Eakin and Luers 2006; Füssel 2007; Moss, Brenkert, and Malone 2001; Ribot 2011). Instead, it relied on local collaboration to identify vulnerability, select and prioritize key areas of concern, and develop adaptation strategies to reduce climate-related vulnerabilities and increase community resilience. Vulnerability is the degree to which a system is susceptible to, or unable 
to cope with, adverse affects of climate change, including climate variability and extremes (Bierbaum et al. 2014). Resilience is the capability to anticipate, prepare for, respond to, and recover from climate impacts with minimum damage (Bierbaum et al. 2014). The approach and the lessons learned from the project could be adapted and applied to a variety of other communities. This paper highlights some of the key insights and lessons learned in applying this approach, focusing on how to use a collaborative process to ensure that science is useful and usable by communities and local decision makers.

\section{Project Description}

\section{Approaching Climate Impacts}

Almost all communities face constraints on time and resources when attempting to prepare for the impacts of climate change and respond to other sustainability issues (Bierbaum et al. 2013; Carmin, Nadkarni, and Rhie 2012; Ford et al. 2010; Measham et al. 2011). The project team used a collaborative approach that leveraged available science and traditional ecological knowledge to more efficiently identify impacts, assess vulnerabilities, and prioritize actions. Current and anticipated climate change impacts affecting the Northern Olympic Peninsula in Washington State are part and parcel of global patterns of change, including increasing temperatures, changing precipitation patterns, sea level rise and coastal flooding, ocean acidification, and habitat change (Intergovernmental Panel on Climate Change 2012, 2013; National Research Council 2010b; Dalton, Mote, and Snover 2013; Littell et al. 2009). Despite the global reach of such issues, local-level planning can lead to successful community response; indeed, such planning has allowed the Tribe to prosper on the Northern Olympic Peninsula for thousands of years.

This project began when the Jamestown S'Klallam Tribal government staff received direction from the Tribal Council to start planning for climate change. This tribe-based directive required an understanding of the Tribe's unique vulnerabilities and adaptive capacity amid the regional, national, and global changes in climate and extreme weather. The first step in climate change planning was to review that broad mix of information, examining it through the lens of what matters most to the Jamestown S'Klallam Tribe.

The project team started by creating a climate change working group. Members of the working group included the Tribal Vice Chair, Tribal Elders, Chief Operations 
Officer, Chief Financial Officer, Economic Development Authority Executive Director, Planning Director, Health Administrator, Facilities Manager, Natural Resource Director, and Natural Resource Managers. Once this team was formed, relevant scientific information on climate change exposure and impacts specific to the Northern Olympic Peninsula was shared with the working group through an initial set of meetings separated into four sector-focused categories: 1) infrastructure, 2) natural resources, 3) economics and finance, and 4) health and social services. These topically focused meetings facilitated detailed discussion of sector-specific impacts and directed the initial identification of key areas of concern. Highlights of the collected and synthesized scientific climate exposure information included the following (see Table 1).

TABLE 1. Climate impacts shared with tribal representatives during sector-focused scoping meetings.

\begin{tabular}{ll}
\hline Climate Variable & Impacts relevant to the Northern Olympic Peninsula \\
\hline Increasing atmospheric temperatures & More frequent and severe extreme heat events, as well as overall atmo- \\
& spheric warming, contributing to warmer river and ocean waters and \\
& reduction in glacier and snowpack mass. These changes have implications \\
& for the health and sustainability of culturally important terrestrial and \\
& freshwater species, along with overall water availability, especially in the \\
& dry season.
\end{tabular}

Changing precipitation patterns

Sea level rise and coastal flooding

Ocean acidification and increasing ocean temperatures

Forest habitat changes
Early snowmelt and reduced snowpack is projected to lead to higher river flows earlier in the year and lower flows during the summer. This will impact river ecology by reducing flows during key migration times and affecting salmon spawning habitats, as well as adding stress to existing competing water demands on rivers.

Project researchers combined global and regional sea level rise projections with local data on vertical land movement (from tectonic plate movement and isostatic rebound) to estimate the relative sea levels in the region over time. The sea level along the shoreline of interest is predicted to rise between 0.5 feet and 2 feet by the year 2050. Sea level rise brings increased risk of coastal flooding and erosion, which may damage homes and other infrastructure and disrupt coastal ecosystems.

Ocean acidification poses a serious threat to the health of shellfish, which the Tribe relies upon for ceremonial, subsistence and commercial harvests, as well as other marine organisms such as phytoplankton, which form the base of many marine food webs. Increased acidity has already been observed in the Strait of Juan de Fuca, and the regional upwelling pattern promotes the acidification of surface-level ocean water. Higher ocean temperatures will also favor heat-tolerant shellfish species, increase thermal stress on a variety of marine species, increase the likelihood of harmful algal blooms, and decrease the reburrowing activity of shellfish.

Wildfires have increased in frequency in the region since 1970. There is serious concern that drier temperatures will increase wildfire risk and shift forest ecosystems in the Jamestown S'Klallam homeland away from a Western Hemlock forest type towards a Douglas Fir forest type. Western red cedar is a critically important cultural resource that relies on a Western Hemlock forest type to thrive. 
TABLE 1. Continued

\begin{tabular}{ll}
\hline Human health & Climate impacts to culturally important plants and animals that nourish \\
physical, emotional and spiritual health of tribal citizens have the potential \\
to harm the community's health. Climate-influenced events such as \\
decreased air quality, increased wildfires, storms, and floods could directly \\
affect human health. Reduced opportunities for subsistence and commer- \\
cial fish and shellfish harvest would impact associated physical activity and \\
nutrition.
\end{tabular}

\section{Collaboration and Co-production of Knowledge}

The structured sector-specific meetings elicited valuable insight, information, and guidance on identifying, analyzing, and prioritizing the community's key areas of concern related to climate change. They also gave structure to the next step, the two-day climate change workshop.

Using a combination of large-group sessions and smaller breakout groups, Day One of the workshop focused on a detailed analysis of the Tribe's key areas of concern. From a theoretical perspective, this detailed analysis included assessment of climate exposure, sensitivity, and adaptive capacity. Climate exposure is the extent and magnitude of a climate and weather event on an area of concern. Sensitivity is the degree to which an area of concern is susceptible to a climate impact. Adaptive capacity is the ability of an area of concern to adjust to or respond to the changing conditions. However, members of the working group cared less about these technical definitions than in the impact of changing climate conditions on important aspects of their lives.

The second day of the workshop focused on verifying Day One decisions and results and creating a detailed prioritization of the Tribe's key climate-related vulnerabilities. Conversations at this workshop flowed in every direction: sometimes, climate change science inspired brainstorming; sometimes, traditional ecological knowledge provided context for issues of climate-influenced environmental change not captured by any of the best available science. For example, a Tribal Elder and cedar bark harvester had noticed that the optimal harvest time for cedar bark had already moved to earlier dates in the springtime. Easy bark removal is generally achieved when a long section of bark can be removed without permanently damaging the tree, and it depends upon a complex suite of variables including temperature, the amount of water available to the tree, and the tree's specific growth processes (Elaine Grinnell, personal communication, January 30, 2013).

The open communication at the workshop illustrated how environmental knowledge is a composite of different types of expertise-from the local and tradi- 


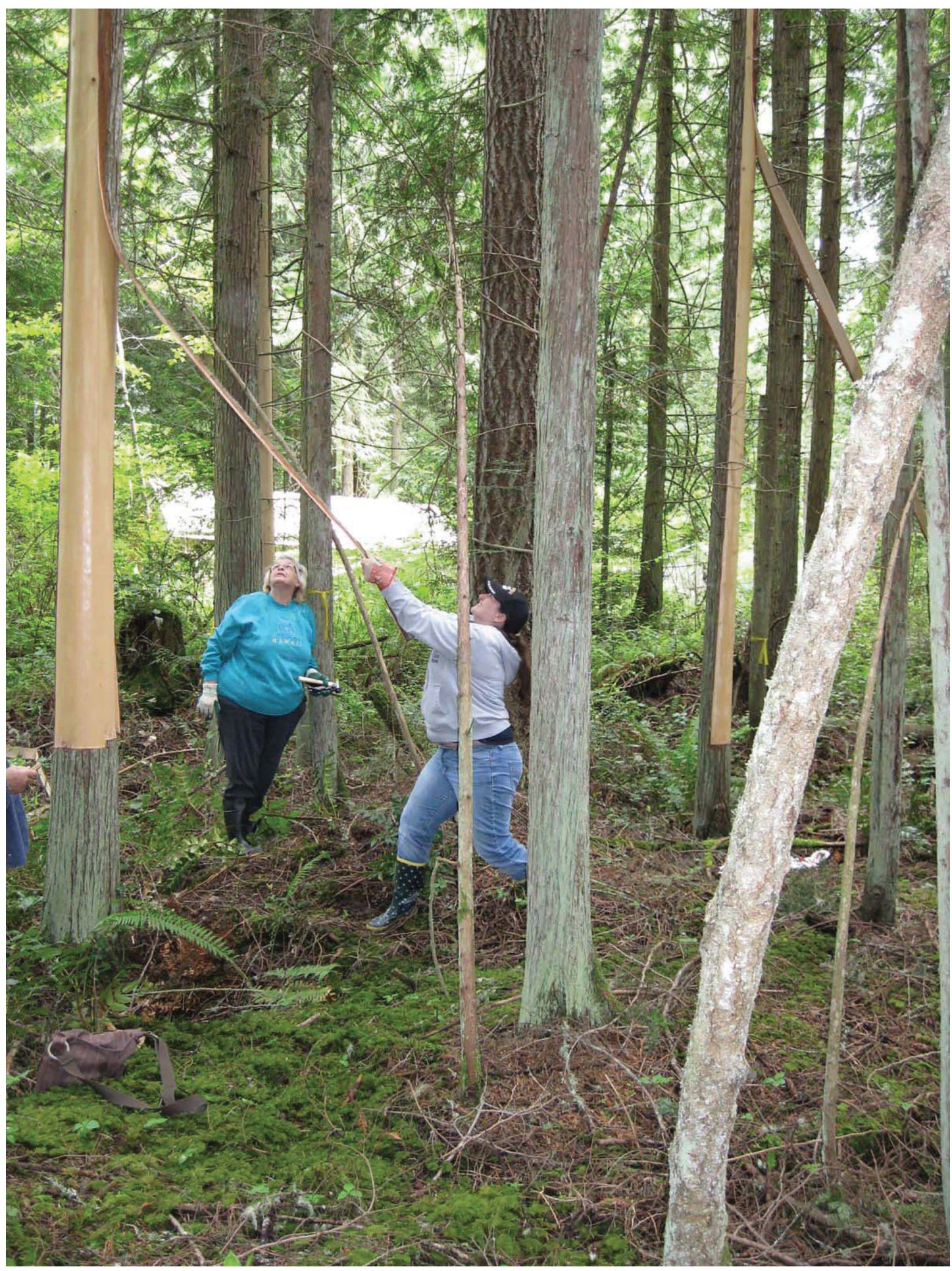

Figure 2. Jamestown citizens harvesting cedar bark. Photo courtesy of the Jamestown S'Klallam Tribe. 
tional to the global and scientific — and highlighted the need for any sustainable discussions of climate impacts and actions to synthesize a diverse range of perspectives.

\section{Key Areas of Concern}

During the workshop, the working group identified the following key areas of concern: Salmon, Clams and Oysters, Shellfish Biotoxins, Wildfire, Cedar Harvest, the Casino and Longhouse Market, Transportation-Highway 101, Tribal Campus Water Supplies, Jamestown Beach Water Supply, Natural Resources Lab and Planning Department Buildings, and Tribal Campus Wastewater Tanks (see Figure 1). After the workshop, participants identified and explored two additional areas of concern focusing on the sea level rise impacts on Jamestown Beach and the shoreline area from the Rivers End to the Jamestown Beach. For each area of concern, workshop attendees participated in discussions of climate exposure, sensitivity, and adaptive capacity in order to determine the overall climate vulnerability (Figure 3).

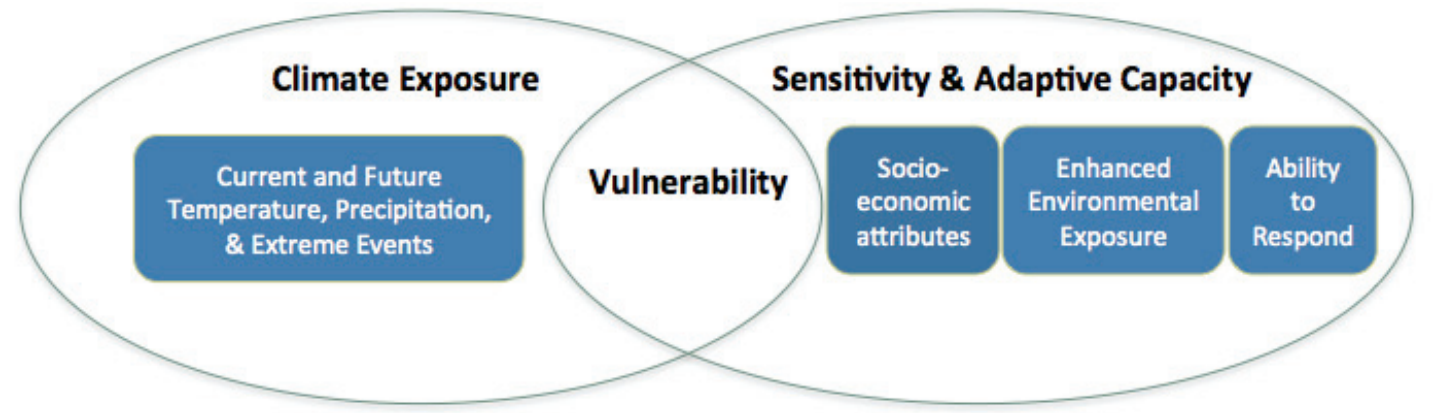

Figure 3. Climate Vulnerability is the degree to which a system is susceptible to, or unable to cope with, adverse effects of climate change, including climate variability and extremes. Climate vulnerability depends on exposure, sensitivity, and adaptive capacity (adapted from IPCC 2012). Climate exposure is the extent and magnitude of a climate and weather event. Sensitivity is the degree to which the area of concern is susceptible to a climate impact. Adaptive capacity it the ability of the area of concern to adjust or respond to the changing conditions.

During workshop breakout sessions, the project team presented a framework for assessing the vulnerability of each key area of concern using the criteria of sensitivity and adaptive capacity (as defined above). Using this framework, the working group assigned a sensitivity ranking (ranging from SO-system will not be affected to S4-system will be greatly affected) and an adaptive capacity ranking (ranging from ACO - system is not able to accommodate or adjust to the impact to AC4-system is able to accommodate or adjust to the impact in a beneficial way) to each key area of 


\begin{tabular}{|c|c|c|c|c|c|c|}
\hline \multicolumn{2}{|c|}{ Vulnerability Ranking Table } & & & & & \\
\hline \multicolumn{7}{|c|}{ Potential opportunity } \\
\hline \multicolumn{7}{|c|}{ Low Vulnerability } \\
\hline \multicolumn{2}{|c|}{ Medium-Low Vulnerability } & \multirow{2}{*}{\multicolumn{5}{|c|}{ Sensitivity Low }} \\
\hline \multirow{2}{*}{\multicolumn{2}{|c|}{$\begin{array}{l}\text { Medium Vulnerability } \\
\text { Medium-High Vulnerability }\end{array}$}} & & & & & \\
\hline & & SO & S1 & S2 & S3 & S4 \\
\hline \multirow{2}{*}{$\begin{array}{l}\text { Adaptive } \\
\text { Capacity }\end{array}$} & $\mathrm{ACO}$ & & & & & \\
\hline & AC1 & & & & & $=0+0$ \\
\hline \multirow{2}{*}{$\begin{array}{l}\text { Low } \\
\downarrow\end{array}$} & $\mathrm{AC2}$ & & & $\omega$ & 48 & $0^{\circ}$ \\
\hline & $\mathrm{AC} 3$ & & & & & 目 \\
\hline High & $\mathrm{AC4}$ & & & & & - $\mathrm{m}$ 孟 \\
\hline
\end{tabular}

Salmon (Long-term)

Clams \& Oysters (Long-term)

Casino and Longhouse Market

Shellfish Biotoxins +

Transportation Hwy 101

Jamestown Beach Water Supply $\boldsymbol{\otimes}$

Tribal Campus Water Supply

Wildfire

Cedar Trees

NR Lab \& Planning Dept. Buildings

Tribal Campus Wastewater Tanks

Figure 4. Relative climate vulnerability rankings for key areas of concern. The placement of each key area of concern on the chart depends on the identified sensitivity and adaptive capacity for that area of concern. All key areas of concern considered during the workshop are shown.

concern. The working group then used those values to rank the relative vulnerability of those areas of concern. The most vulnerable areas have the highest sensitivity and the lowest adaptive capacity. The least vulnerable areas have the lowest sensitivity and the highest adaptive capacity. Figure 4 displays all key areas of concern in this vulnerability matrix.

Finally, these key areas of concern were prioritized for planning response according to seven criteria (Intergovernmental Panel on Climate Change 2007):

- Magnitude of Impacts- the scale and intensity of the climate impact;

- Timing of Impacts- when the impact is likely to occur;

- Persistence and Reversibility - how long lasting or irreversible the impacts are; 
- Likelihood of Impacts- how likely is it for the impact to occur;

- Distributional Nature of Impacts- whether specific groups or the whole community would be impacted;

- Importance of System at Risk- the cultural, economic, or social value of the system affected; and

- Potential for Adaptation - the availability and feasibility of actions to prepare for or respond to the climate impacts.

The full working group split into two subgroups. For each key area of concern, the groups scored each criterion on a scale of 1 to 5 (with 1 being the smallest impact and 5 being the highest level of impact). The "Potential for Adaptation" criterion was scored on a reverse scale with a score of 1 corresponding to a high potential to adapt and 5 corresponding to a low potential to adapt. The scores were then added and averaged across the groups to create a final score. Prioritization of the key areas of concern resulted in the rankings shown in Table 2. Interestingly, the prioritizations naturally fell into distinct groupings of concerns, which were labeled Very High Priority, High Priority, and Medium Priority.

TABLE 2. Prioritization of key areas of concern during the Tribal Climate Change Workshop

\begin{tabular}{lll}
\hline Very High Priority & High Priority & Medium Priority \\
\hline Salmon & Highway 101 & Jamestown Beach Water Supply \\
Clams and Oysters & Casino and Longhouse Market & Tribal Campus Wastewater Tanks \\
Shellfish Biotoxins & Tribal Campus Water Supplies & Natural Resources Lab and Planning \\
Wildfire & & Department Buildings \\
Cedar Harvest & &
\end{tabular}

The identification of key areas of concern allowed the Tribe to move forward with a concept of climate change impact and adaptation that was relevant to its priorities and the intricacies of the local environment. This "customized" climate change perspective was a crucial step for organization-level adaptation planning.

\section{Project Outputs}

Following the conclusion of the workshop, the project team resumed work on a comprehensive climate change impact analysis for the community. All of this work was summarized in a report entitled Climate Vulnerability Assessment and Adaptation Plan that includes all of the scientific data and information discussed by the Tribal stakeholders. It also contains in-depth descriptions of key areas of concern, 
including why the resource is important to the Tribe, potential climate impacts to the resource, and actions to increase resilience of the resource in the face of climate change. The two key areas of concern summarized below illustrate the breadth of impacts covered by the report.

\section{Key Areas of Concern}

\section{Summary 1: Clams and Oysters, Vulnerability = High, Priority = Very High}

Clams and oysters have been an integral part of tribal life for the Jamestown S'Klallam people throughout their history. Tribal citizens continue to participate in subsistence and commercial harvest of littleneck and manila clams, oysters, shrimp, crab, mussels, and geoducks (a very large local shellfish). Of these, geoducks and crab provide the largest annual harvest (Kelly Toy, personal communication, January 29, 2013). Harvesting of geoducks is economically important for the Tribe, generating revenue that supports Tribal Government operations and local employment. Although less economically valuable, intertidal shellfish, particularly clams and oysters, are culturally and nutritionally important for the Tribe. Traditional foods such as shellfish provide a nutrient-rich and culturally important component of the modern diet, and harvesting and processing activities are associated with a less sedentary lifestyle (Bennett et al. 2012). Additionally, local fishing is considered a top contributor to physical activity among tribal citizens (Cindy Lowe, personal communication, January 14, 2013). Finally, there are few financial barriers to personal harvesting of clams and oysters, which makes them the most easily accessed and well-distributed subsistence resource among tribal citizens (Cindy Lowe, personal communication, February 25, 2013).

There are shellfish harvest beaches throughout the region, although some beaches are more consistently used for subsistence harvest. Such diets and lifestyles provide food packed with essential fatty acids, antioxidants, and protein and are associated with prevention and mitigation of chronic diseases such as diabetes, heart disease, and cancer (Egeland, Feyk, and Middaugh 1998).

Clams and oysters face serious threats from changing climate conditions. The concerns come primarily from changing habitat conditions due to warming water temperatures and increasing ocean acidity. Rising temperatures will favor more heattolerant shellfish species, increase overall suffering from thermal stress, and decrease 
reburrowing activity (the means by which shellfish rebury themselves) (Freitas et al. 2007). As studied under laboratory conditions, shellfish generally exhibit negative responses to elevated carbon dioxide $\left(\mathrm{CO}_{2}\right)$ concentrations and reduced $\mathrm{pH}$ (higher acidity); in effect, they are forced to exert more energy to build their shells and prosper (Feeley et al. 2012; Fernández-Reiriz et al. 2011; Freitas et al. 2007). Higher air temperatures during low tide when the shellfish are exposed may cause additional stress to these species.

Commercial Pacific oyster larvae operations in Washington and Oregon have recently suffered from increases in corrosive seawater, particularly during major upwelling events where winds push surface water away from the shoreline and deep ocean water rises to the surface to take the place of the water that was pushed away. Upwelled water has naturally higher concentrations of $\mathrm{CO}_{2}$ and lower $\mathrm{pH}$, providing a glimpse into a future ocean under acidification conditions. Starting in the mid-2000s, commercial oyster hatchery operations in Washington and Oregon experienced "production failure" levels of larval death (Feeley et al. 2012). Increasing acidification of the water negatively impacted both larval production and midstage growth of the oysters (Barton et al. 2012).

Efforts to help clams and oysters become more resilient to climate change focus primarily on reducing or eliminating existing stressors, thereby increasing overall adaptive capacity and resilience.

\section{Summary 2: Jamestown Beach Water Supply, Vulnerability = Medium, Priority $=$ Medium}

Jamestown Beach is the historic settlement of the ancestors of the S'Klallam Tribe. Following the signing of the Treaty of Point No Point in 1855, the S'Klallams were determined to stay near their traditional fishing areas. In 1874, tribal citizens pooled their money and purchased 210 acres near the mouth of the Dungeness River, the major fishery of the local S'Klallams (Jamestown S'Klallam Tribe 2014). This area is known today as Jamestown.

The homes located along Jamestown Beach Road, including tribal residences, all receive their water from a local well. The Tribe is responsible for well operation and also owns a number of properties in the area. This is the single potable water source for the homes along the beach, as well as many homes inland.

Any inundation of the lands immediately above or surrounding the well may introduce contaminants into the water source. Coastal flooding may also compromise drinking water quality and should be followed by appropriate testing to ensure that 


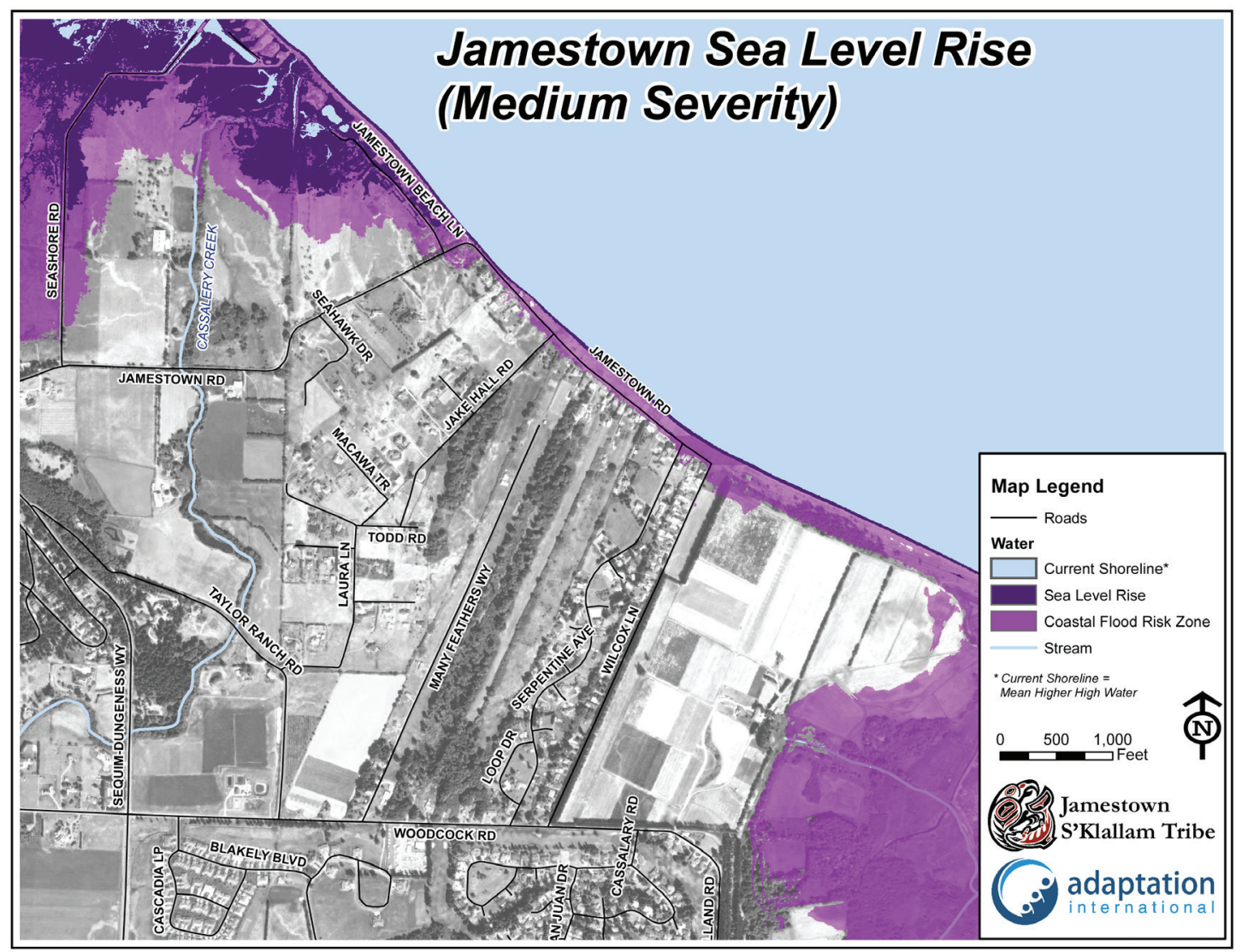

Figure 5. Jamestown Beach medium-severity sea level rise (about 2 feet). Inundation and storm surges are projected to occur between 2055 and 2090.

water meets quality standards. These scenarios highlight the potential climate- and weather-related exposure of the well but do not take into account the potential for salt water intrusion into the well or damage to the well housing, which could occur during sea level rise even in the absence of extreme flooding.

The scenario of a medium-severity sea level rise illustrated in Figure 5 is not projected to occur for a number of decades (it could take place between 2055 and 2090). However, the map in Figure 5 does not incorporate dynamic shoreline processes like the potential for increased erosion or disruption of groundwater inputs to the well, nor does it include projections of changes in wave dynamics or storm orientations that could further exacerbate high water levels on Jamestown Beach. These processes, which are not included in the scenarios mapped for the Tribe (Miller et al. 2014), may increase the extent and magnitude of coastal flooding and may damage the well sooner than the sea level rise maps project. 
The well was ranked medium vulnerability due to the medium-term nature of the climate exposure. It was also ranked as a medium priority: although a well or pump failure would have a significant impact on the tribal citizens who receive water from the well, those individuals represent a small subset of the full tribal community and would continue to have access to other water sources in the greater Sequim region.

The Indian Health Service installed the Jamestown Beach well in the 1960s; although it is still working, it should be replaced. The most cost-effective opportunity to decrease the vulnerability of the well to coastal flooding is to conduct any retrofitting or relocation at the time of its replacement.

\section{Exploring Adaptation Opportunities}

For each key area of concern, the project team and working group discussed relevant "best practice" adaptation methods taken from the literature, case studies, and personal experience; tailored these strategies to the local context; and brainstormed additional strategies when appropriate (see Tables 3 and 4). Although the identified potential adaptation strategies were not fully prioritized during this project period, the tribe has already initiated internal planning discussions regarding some of these actions. The team also developed an evaluation process to prioritize adaptation strategies and actions according to five criteria: cost, ease of implementation, political/community support, timing of action, and partnerships required.

Tables 3 and 4 present two lists of potential adaptation strategies the Tribe is considering. The two tables correspond to the two key areas of concern summarized above, Clams and Oysters (Table 3) and the Jamestown Beach Water Supply (Table 4).

\section{Public Engagement}

As in many scientific and sustainability issues, those working on climate change have frequently struggled to bridge the gap between professionals in the field and citizens working to address these issues in their daily lives (Berke and Lyles 2013; Hobson and Niemeyer 2011; Tompkins and Eakin 2012). Collaboration with the tribal working groups led to the relevant and actionable Climate Vulnerability Assessment and Adaptation Plan for the Tribe itself, but this report is not an accessible document for the general public or for many tribal citizens due to its length, techni- 
TABLE 3. Resilience strategies for clams and oysters. This table provides a select list of key actions to increase resilience, as well as a number of criteria to be used in the evaluation, prioritization, and selection of strategies.

\begin{tabular}{|c|c|c|c|c|c|}
\hline Clams, Oysters, and Shellfish Biotoxins ${ }^{1}$ & Cost & $\begin{array}{c}\text { Ease of } \\
\text { Implementation }\end{array}$ & $\begin{array}{l}\text { Political/ } \\
\text { Community } \\
\text { Support }\end{array}$ & $\begin{array}{l}\text { Timing of } \\
\text { Action }\end{array}$ & $\begin{array}{l}\text { Partnerships } \\
\text { Required }\end{array}$ \\
\hline $\begin{array}{l}\text { Monitor and continue to improve local water quality } \\
\text { since a significant amount of bivalve-species decline is } \\
\text { associated with water-quality degradation. Consider } \\
\text { expanding monitoring to include continuous water } \\
\text { temperature and } \mathrm{pH} \text {. }\end{array}$ & Medium & Hard & High & $\begin{array}{l}\text { Medium- } \\
\text { Term }\end{array}$ & $\begin{array}{l}\text { Yes (surrounding } \\
\text { communities, } \\
\text { state, private } \\
\text { land owners) }\end{array}$ \\
\hline Ensure sustainable harvesting of clams and oysters. & Low & Moderate & High & Immediate & $\begin{array}{l}\text { Yes (with state, } \\
\text { industry, other } \\
\text { tribes) }\end{array}$ \\
\hline Rebuild stocks (i.e., restoration). & Medium & Moderate & Medium & $\begin{array}{l}\text { Medium- } \\
\text { Term }\end{array}$ & $\begin{array}{l}\text { Yes (with state } \\
\text { Department } \\
\text { of Natural } \\
\text { Resources } \\
(\text { DNR)) }\end{array}$ \\
\hline $\begin{array}{l}\text { Hatchery propagation and restocking of populations } \\
\text { in areas where natural reproduction of native bivalves } \\
\text { is limited. If this is pursued, ensure that replaced } \\
\text { stocks are indigenous to the area (Marlin Holden, } \\
\text { personal communication, February } 7,2013 \text { ). }\end{array}$ & Medium & Easy & Medium & Immediate & $\begin{array}{l}\text { Yes (with state } \\
\text { DNR) }\end{array}$ \\
\hline $\begin{array}{l}\text { Transplanting adult clams and oysters (assisted } \\
\text { migration) from remnant populations into areas that } \\
\text { are more suitable for reproductive success. }\end{array}$ & Medium & Moderate & Medium & Immediate & $\begin{array}{l}\text { Yes (with state } \\
\text { DNR) }\end{array}$ \\
\hline $\begin{array}{l}\text { Develop cultural center and traditional longhouse } \\
\text { around Harvest Beach in Blyn to enhance under- } \\
\text { standing of shellfish heritage and engage more Tribal } \\
\text { Citizens in harvesting clams and oysters. }\end{array}$ & Medium & Easy & Medium & Immediate & No \\
\hline
\end{tabular}

${ }^{1}$ Qualitative metrics are as follows: Cost (Low, Medium, High); Ease of Implementation (Easy, Moderate, Hard); Political/Community Support (Low, Medium, High); Timing of Action (Immediate, Medium-Term, Long-Term); Required Partnerships (Yes, No). Example adaptation actions adapted from Kreeger et al., 2010 except as noted.

cal language, and comprehensive breadth. For this reason, the project team revisited the key areas of concern and created straightforward and graphically rich two-page summaries for each. These summaries were designed primarily for tribal citizens and potential tribal partners who may not access the main report. The documents themselves are visually attractive and available individually, which allows citizens to easily explore the topics of particular interest to them. A sample summary sheet appears in Figure 6. 
TABLE 4. Resilience strategies for Jamestown Beach well. This table provides a select list of key actions to increase resilience of the Jamestown Beach water supply, as well as a number of criteria to be used in the evaluation, prioritization, and selection of strategies.

\begin{tabular}{|c|c|c|c|c|c|}
\hline Jamestown Beach Water Supplies ${ }^{2}$ & Cost & $\begin{array}{c}\text { Ease of } \\
\text { Implementation }\end{array}$ & $\begin{array}{l}\text { Political/ } \\
\text { Community } \\
\text { Support }\end{array}$ & $\begin{array}{l}\text { Timing of } \\
\text { Action }\end{array}$ & $\begin{array}{l}\text { Partnerships } \\
\text { Required }\end{array}$ \\
\hline $\begin{array}{l}\text { Conduct a hydrological connectivity ground- } \\
\text { water assessment to evaluate the potential for } \\
\text { saltwater intrusion with an elevated water table } \\
\text { as sea levels rise. }\end{array}$ & Medium & Medium & Medium & Immediate & No \\
\hline $\begin{array}{l}\text { Evaluate the potential to connect area residences } \\
\text { to a secondary water supply. }\end{array}$ & Low & Medium & High & $\begin{array}{l}\text { Immediate } \\
\text { to Medium- } \\
\text { Term }\end{array}$ & No \\
\hline $\begin{array}{l}\text { Ensure that any new well is sited outside of } \\
\text { coastal flood zones. Include this concern when } \\
\text { requesting funding from the Indian Health } \\
\text { Service or others to replace or relocate the well. }\end{array}$ & Low & Medium & High & $\begin{array}{l}\text { Medium- } \\
\text { Term }\end{array}$ & No (on tribal land) \\
\hline $\begin{array}{l}\text { Following any major flood event, conduct well- } \\
\text { water sampling to ensure that water meets safety } \\
\text { standards. }\end{array}$ & Low & Easy & High & Immediate & No \\
\hline
\end{tabular}

${ }^{2}$ Qualitative metrics are as follows: Cost (Low, Medium, High); Ease of Implementation (Easy, Moderate, Hard); Political/Community Support (Low, Medium, High); Timing of Action (Immediate, Medium-Term, Long-Term); Required Partnerships (Yes, No).

\section{Potential Limitations and Barriers}

This community assessment approach is not without potential limitations and barriers. In order to facilitate ongoing improvement of this process, it is important to be explicit and transparent about these concerns. First, while the climate exposure information does represent the best available science available at the time of project implementation, it relies on a variety of assumptions and contains inherent uncertainty. For example, the coastal flood-risk maps are based on the current shoreline profile and do not include estimates of potential dynamic shoreline response or erosion based on higher sea levels and more frequent coastal flooding. The sea level rise scenarios also assumed linear and non-varying rates of vertical land movement and used historical storm patterns as a basis for future projections. Time will certainly prove some of these assumptions invalid, which will impact local-level planning for sea level rise (Miller et al. 2014).

Second, the project did use a scenario planning process to explore the uncertainty related to these estimates and global sea level rise, but it could improve upon the outstanding uncertainties in the future by incorporating more reliable data on 
storm surge return frequencies, vertical land movement, and shoreline response due to rising sea levels. Unfortunately, current projections related to future air temperature, precipitation amounts, ocean acidification, and other variables also suffer from many uncertainties in their actualization at the local level. This project aimed to initiate an ongoing climate change assessment and adaptation process at the local level, and participants realize that planning will be relevant only if it can successfully incorporate advances in climate science and projection as they become available.

Finally, community engagement is always an incomplete process, and we can safely assume that this project did not capture all relevant traditional ecological knowledge throughout the community. The process captured only the knowledge of those participating in the working group. The tribal community is much larger than this group, and learning from other tribal citizens will be an ongoing process now that this project has started the community conversation on preparing for the impacts of climate change. This project was fortunate to have a set of highly motivated tribal representatives, but without such local leadership, a similar project in another location could be left with less than adequate participation in the crucial collaborative steps of scoping, vulnerability prioritization, and identifying opportunities to build resilience. At all steps of the project, it is important to remain open to sharing new knowledge and answering additional questions, whether that new information emerges from climate science or from traditional ecological knowledge.

\section{Conclusion}

\section{The Usefulness of Key Areas of Concern}

Communities and organizations facing climate change are time and resource constrained, yet they face a substantial number of environmental changes and impacts that are expected to continue for the foreseeable future (Carmin, Nadkarni, and Rhie 2012; Wiener 2007; Intergovernmental Panel on Climate Change 2013). This can be a daunting task. As Ron Allen, the Jamestown S'Klallam Tribal Chairman, put it earlier this year, "The enormity of the issues feels overwhelming. Yet, the S'Klallam culture promotes self-sufficiency and leadership, so we must do what we can. Our greatest barrier to success is the failure to plan" (Allen 2014).

Moving forward with a local approach to addressing climate change under these circumstances requires careful assessment of scientific data, conceptualization of 


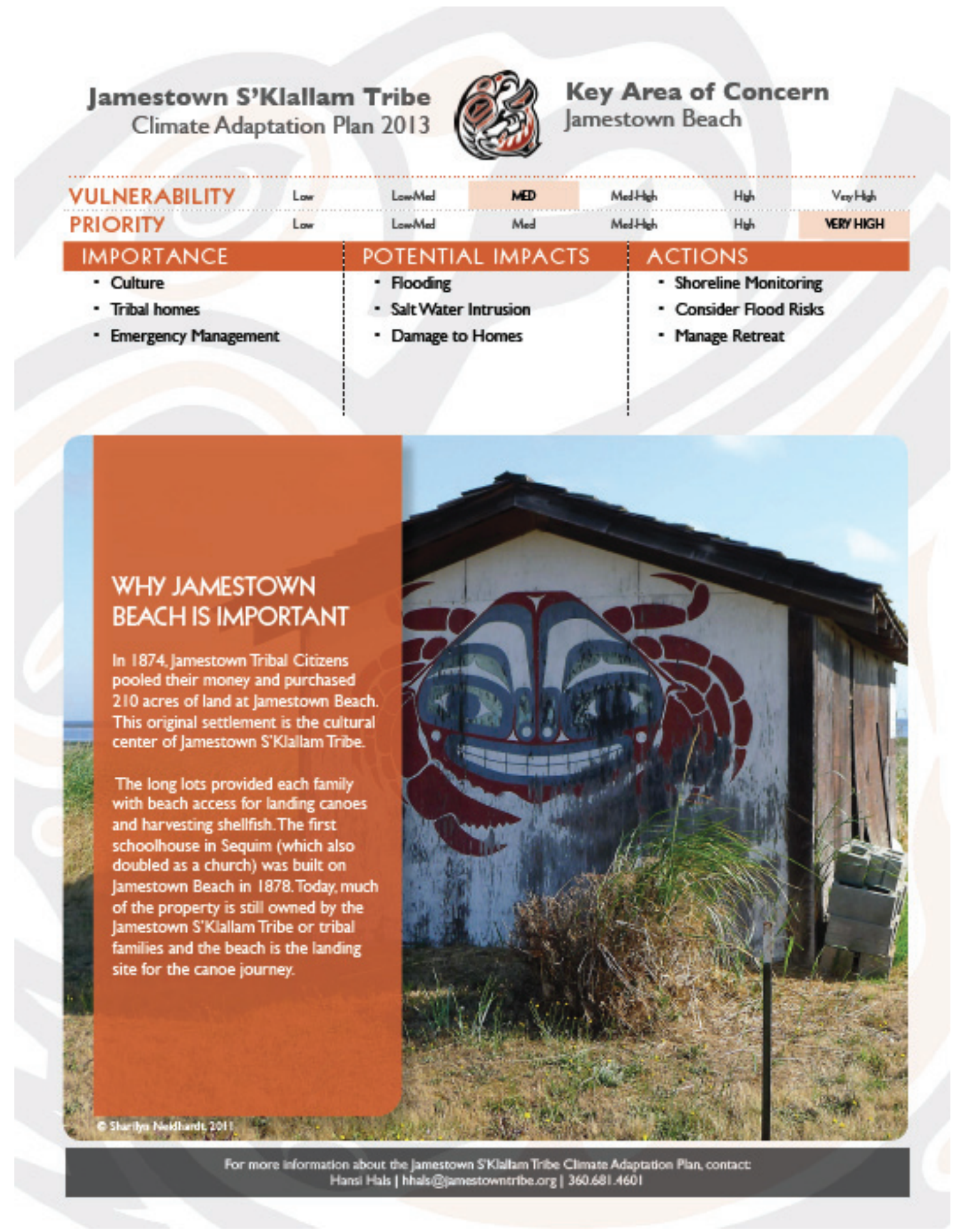




\section{POTENTIAL IMPACTS} OF CLIMATE CHANGE

By mid-century, many of the houses along Jamestown Beach Road will be at-risk of flooding from during severe storms events. The flooding could range from minor water damage to substantial sediment and debris in the first floor of the houses. Sea level rise may elevate the water table and flood septic systems, causing local water quality problems from the release of untreated sewage. Flooding may also temporarily close Jamestown Road, preventing emergency service access or limiting the resident's ability to leave and find shelter.

- Flooding

- Saltwater intrusion

- Damage to homes

- Temporary loss of access

- Impaired emergency services

\section{SEA LEVEL RISE}

This map shows potential inundation during high tides (dark purple) and the coastal flood risk zone (light pink) for Jamestown Beach under the high severity sea level rise scenario projected to occur near the end of the century.

\section{ACTIONS TO INCREASE RESILIENCE}

Monitoring of the shoreline will help the Tribe and Jamestown Beach residents determine how the shoreline is responding to changing sea levels and identify the areas most at risk for flooding. Longer-term options for protecting or relocating buildings should be discussed.
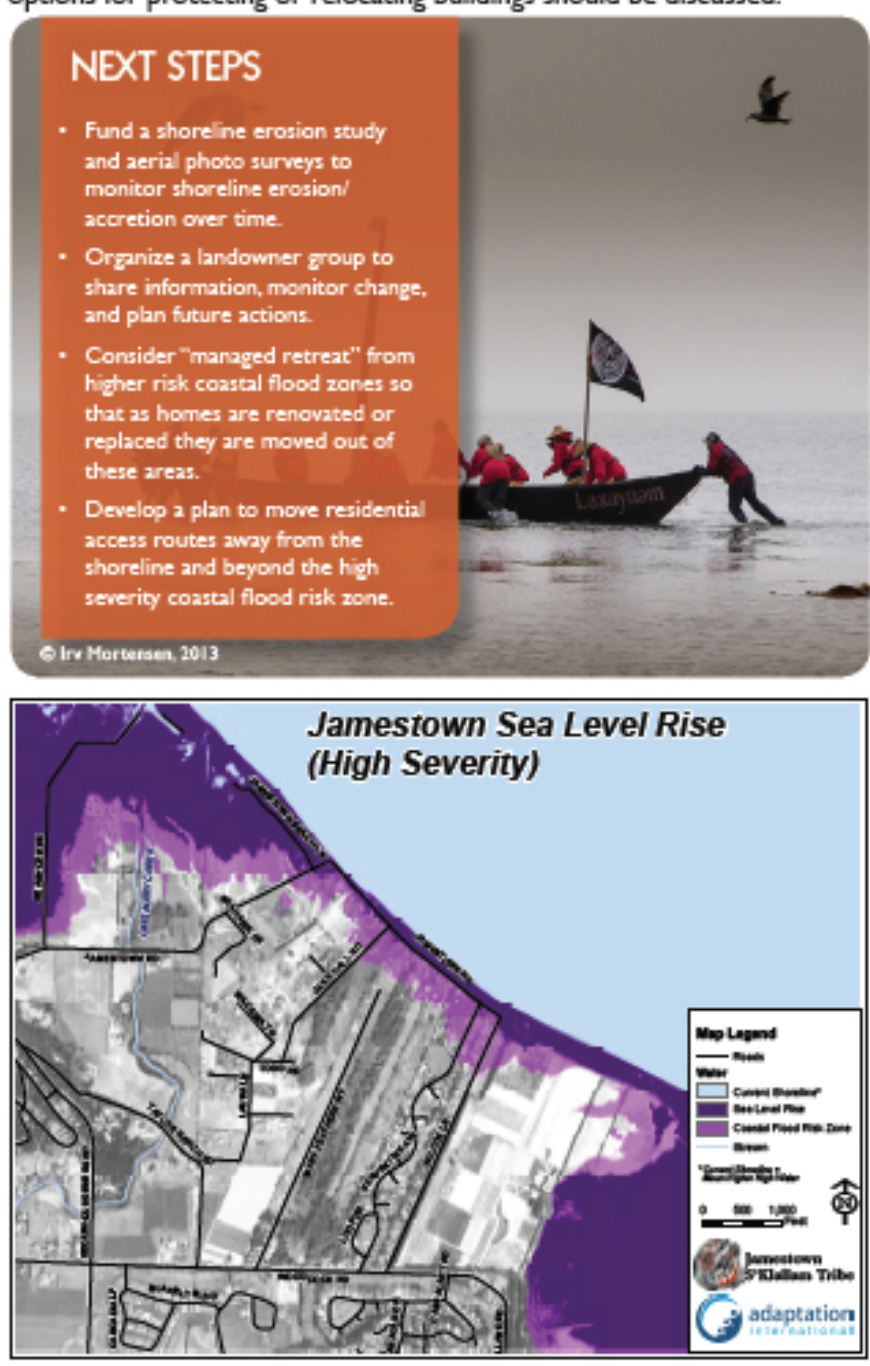

Tht document was peepared by Adepeatioa International We beas on helping comnunities, tuinestes, and ergantations prepare for the impacts of a changing climate.

(2) adaptation

wromcadoptackonimterational com Copyright OAdaptatios Imternational 2013

Figure 6. Key Area of Concern summary sheet for Jamestown Beach. This is an example of the graphically rich summaries designed primarily for education and outreach. 
meaningful impacts, and targeted prioritization and action. The methods involved in this project ensured that local collaboration guided climate change planning without departing from the most recent scientific modeling or best-practice adaptation scenarios. As climate change impacts and risks cross sectors and geography, community responses must also incorporate knowledge across sectors and organizations. The key area of concern approach acknowledges all of these realities and allows community members to focus their limited time and resources on the areas or assets that are most important to them. For the Jamestown S'Klallam Tribe, this focus generally increased understanding of how climate change will impact the community and the strategies available to reduce vulnerability and build resilience to those impacts. This approach could be used to enhance progress on other sustainability issues that present the same challenges of limited time and resources.

For the Tribal Government staff, the project report and especially the Key Areas of Concern summary sheets are useful communication tools. Presentations have been made to the Tribal Council and Department Directors to inform them of the results of the assessment and to see how addressing these concerns fits into shortterm planning priorities. The summary sheets have also proven extremely useful for audience members who have little technical knowledge about climate change. In fact, all Tribal Council members have one or two particular concerns that most interests them, and they have retained personal copies of those summary sheets for their own outreach.

Preparing for the impacts of climate change, like addressing other sustainability issues, is not an outcome but a process. By taking an approach that focuses on key areas of concern and combines the best available science with community and social values, the Jamestown S'Klallam Tribe has laid the foundation for that process. In some ways, climate change is just one more issue to consider when creating a more sustainable community, protecting and maintaining important resources and assets, ensuring continued economic growth, and promoting long-term community and cultural vitality.

\section{Next Steps for the Tribe}

The Jamestown S'Klallam Tribal Government and tribal citizens are well poised to successfully prepare for changing climate conditions on the Olympic Peninsula. The ongoing efforts of the Tribal Natural Resource Department, Health Department, and others have created a foundation for moving from climate planning to action. The Tribe has been responding and adapting to a changing climate for thousands of 
years. Thus, preparing for ongoing and accelerating change is not something new, but a continuation of the culturally driven, natural resource-oriented approach that has kept the Tribe a vibrant and growing community.

A portion of the climate change working group reconvened on April 22, 2013 to discuss the detailed findings of the project, review the actions to increase resilience, and discuss next steps. In collaboration with other stakeholders, the working group identified four next steps to help the Tribe move forward in preparing for climate change. They are 1) prioritizing adaptation strategies for implementation and identifying individuals or departments responsible for implementation; 2) building community support for climate preparedness; 3) incorporating climate preparedness into the Tribal Government operations and policies; and 4) collaborating with surrounding communities, the county, and other key stakeholders to monitor key changes to local and regional climate that are likely to affect the Tribe.

The Tribe has moved forward in each of these areas by presenting the results of the project to the Tribal Executive Committee, by holding meetings with representatives of the surrounding County to discuss coastal flood risk and land use, and by beginning to prioritize adaptation actions. The Jamestown S'Klallam Tribe's climate vulnerability assessment initiated the ongoing process of increasing climate resilience, adapting to a changing environment, and enhancing overall sustainability throughout the community.

\section{References}

Allen, Ron. 2014. “It's Time: Address Climate Change.” Peninsula Daily News. January 3-4.

Barton, A., B. Hales, G. G. Waldbusser, C. Langdon, and R. A. Feely. 2012. "The Pacific Oyster, Crassostrea gigas, Shows Negative Correlation to Naturally Elevated Carbon Dioxide Levels: Implications for Near-term Ocean Acidification Effects." Limnology and Oceanography 57 (3): 698-710.

Bennett, T. M. B., and N. G. Maynard (Convening Lead Authors), P. Cochran, B. Gough, K. Lynn, and G. Voggesser, (Lead Authors). 2012. "Chapter 2: Impacts of Climate Change on Tribal, Indigenous, and Native Lands and Resources." In Draft Climate Assessment Report Released for Public Review. National Climate Assessment. http://ncadac.globalchange.gov.

Berke, P., and W. Lyles. 2013. "Public Risks and the Challenges to Climate-Change Adaptation: A Proposed Framework for Planning in the Age of Uncertainty." Cityscape: A Journal of Policy Development and Research 15 (1): 181-209.

Bierbaum, R., A. Lee, J. Smith, M. Blair, L. M. Carter, F. S. Chapin III, P. Fleming, S. Ruffo, S. McNeeley, M. Stults, L. Verduzco, and E. Seyller. 2014. "Chapter 28: Adaptation.” Climate Change Impacts in the United States: The Third National Climate Assessment, edited by J. M. 
Melillo, Terese (T. C.) Richmond, and G. W. Yohe. U.S. Global Change Research Program: 670-706. doi:10.7930/J07H1GGT.

Bierbaum, Rosina, Joel B. Smith, Arthur Lee, Maria Blair, Lynne Carter, F. Stuart Chapin III, Paul Fleming, Susan Ruffo, Missy Stults, Shannon McNeeley, Emily Wasley, and Laura Verduzco. 2013. "A Comprehensive Review of Climate Adaptation in the United States: More Than Before, but Less Than Needed." Mitigation and Adaptation Strategies for Global Change 18 (3): 361-406. doi:10.1007/s11027-012-9423-1.

Brubaker, Michael, J. N. Bell, J. E. Berner, and J. A. Warren. 2011. "Climate Change Health Assessment: A Novel Approach for Alaska Native Communities." International Journal of Circumpolar Health 70 (3) 266-273. doi:10.3402/ijch.v70i3.17820.

Carmin, J., N. Nadkarni, and C. Rhie. 2012. Progress and Challenges in Urban Climate Adaptation Planning: Results of a Global Survey. Cambridge, MA: MIT.

Cordalis, D., and D. B. Suagee. 2008. "The Effects of Climate Change on American Indian and Alaska Native Tribes." Natural Resources and the Environment 22 (3): 45-49.

Dalton, M. M., P. W. Mote, and A. K. Snover (eds.). 2013. Climate Change in the Northwest: Implications for Our Landscapes, Waters, and Communities. Washington, DC: Island Press.

Eakin, H., and A. L. Luers. 2006. "Assessing the Vulnerability of Social-Environmental Systems." Annual Review of Environment and Resources 31 (1): 365-394. doi:10.1146/annurev.energy.30.050504.144352.

Egeland, G. M., L. A. Feyk, and J. P. Middaugh. 1998. "The Use of Traditional Foods in a Healthy Diet in Alaska: Risks in Perspective." Section of Epidemiology, Alaska Division of Public Health, Department of Health and Social Services, State of Alaska. http://www.epi.hss.state. ak.us/bulletins/docs/rr1998_01.pdf.

Feely, R. A., T. Klinger, J. A. Newton, and M. Chadsey. 2012. "Scientific Summary of Ocean Acidification in Washington State Marine Waters." Washington State Blue Ribbon Panel on Ocean Acidification. https://fortress.wa.gov/ecy/publications/SummaryPages/1201016.html.

Fernández-Reiriz, M. J., P. Range, X. A. Álvarez-Salgado, and U. Labarta. 2011. "Physiological Energetics of Juvenile Clams Ruditapes decussatus in a High $\mathrm{CO}_{2}$ Coastal Ocean." Marine Ecology Progress Series 433:97-105.

Ford, J. D., T. Pearce, F. Duerden, C. Furgal, and B. Smit. 2010. "Climate Change Policy Responses for Canada's Inuit Population: The Importance of and Opportunities for Adaptation." Global Environmental Change 20 (1): 177-191. doi:10.1016/j.gloenvcha.2009.10.008.

Freitas, V., J. Campos, M. Fonds, and H. Ven der Veer. 2007. "Potential Impact of Temperature Change on Epibenthic Predator-bivalve Prey Interactions in Temperate Estuaries." Journal of Thermal Biology 32 (6): 328-340.

Füssel, H.-M. 2007. "Vulnerability: A Generally Applicable Conceptual Framework for Climate Change Research.” Global Environmental Change 17 (2): 155-167. doi:10.1016/j.gloenvcha.2006.05.002.

Hobson, K., and S. Niemeyer. 2011. "Public Responses to Climate Change: The Role of Deliberation in Building Capacity for Adaptive Action." Global Environmental Change 21 (3): 957-971. doi:10.1016/j.gloenvcha.2011.05.001.

Intergovernmental Panel on Climate Change. 2007. Chapter 19: "Assessing Key Vulnerabilities and the Risk from Climate Change." In Climate Change 2007: Impacts, Adaptation and Vulnerability. Contribution of Working Group II to the Fourth Assessment Report of the Intergovernmental 
Panel on Climate Change, edited by M.L. Parry, O.F. Canziani, J.P. Palutikof, P.J. van der Linden and C.E. Hanson, Eds., Cambridge University Press, Cambridge, UK, 779-810.

. 2012. Managing the Risks of Extreme Events and Disasters to Advance Climate Change Adaptation: Special Report of the Intergovernmental Panel on Climate Change, edited by Christopher B. Field, Vicente Barros, Thomas F. Stocker, Qin Dahe, David Jon Dokken, Gian-Kasper Plattner, Kristie L. Ebi, Simon K. Allen, Michael D. Mastrandrea, Melinda Tignor, Katharine J. Mach, and Pauline M. Midgley. Cambridge, UK and New York: Cambridge University Press. doi:10.1017/CBO9781139177245.

- 2013. "Summary for Policymakers." In Climate Change 2013: The Physical Science Basis. Contribution of Working Group I to the Fifth Assessment Report of the Intergovernmental Panel on Climate Change, edited by V. B. and P. M. M. Stocker, T. F., D. Qin, G.-K. Plattner, M. Tignor, S.K. Allen, J. Boschung, A. Nauels, and Y. Xia, 28. Cambridge, UK and New York: Cambridge University Press.

International Institute for Indigenous Resource Management. 2010. Final Report of the Roundtable to Identify the Scientific Research Agenda to Build Tribal Resilience to Effects of Climate Change Mitigation and Adaptation Activities in Indian Country. Denver, Colorado. http://earthlodge. net/files/8713/2947/6896/Final\%20Report\%20with\%20appendices.pdf

Intertribal Climate Change Working Group. 2009. "A Tribal White Paper on Climate Change Adaptation and Mitigation From the Intertribal Climate Change Working Group." August 13, p 13.

Jamestown S’Klallam Tribe. 2014. “Jamestown S’Klallam History.” http://www.jamestowntribe. org/history/hist_jst.htm.

Kreeger, D., J. Adkins, P. Cole, R. Najjar, D. Velinsky, P. Conolly, and J. Kraeuter. 2010. “Climate Change and the Delaware Estuary: Three Case Studies in Vulnerability Assessment and Adaptation Planning." Partnership for the Delaware Estuary, PDE Report No. 10-01. http:// delawareestuary.org/pdf/Climate/Climate\%20Change\%20and\%20the\%20Delaware\%20Estuary_PDE-10-01.pdf.

Lamb, R., and M. V. Davis. 2011. Promoting Generations of Self-Reliance: Stories and Examples of Tribal Adaptation to Change. U.S. Environmental Protection Agency Region 10, Seattle, p 27.

Littell, J. S., M. McGuire Elsner, L. C. Whitely Binder, and A. K. Snover (Eds). 2009. "The Washington Climate Change Impacts Assessment: Evaluating Washington's Future in a Changing Climate-Executive Summary." In The Washington Climate Change Impacts Assessment: Evaluating Washington's Future in a Changing Climate. Seattle: Climate Impacts Group, University of Washington. www.cses.washington.edu/db/pdf/wacciaexecsummary638.pdf.

Mariella, P., E. Brown, M. Carter, and V. Verri. 2009. “Tribally Driven Participatory Research: State of the Practice and Potential Strategies for the Future." Journal of Health Disparities Research and Practice 3 (2): 41-58.

Measham, T. G., B. L. Preston, T. F. Smith, C. Brooke, R. Gorddard, G. Withycombe, and C. Morrison. 2011. "Adapting to Climate Change through Local Municipal Planning: Barriers and Challenges." Mitigation and Adaptation Strategies for Global Change 16 (8): 889-909. doi:10.1007/s11027-011-9301-2.

Miller, I. M., S. Petersen, B. Rot, H. Hals, J. Parks, P. Edens, and J. Bell. 2014. "PDOs and Slow Slip and Storm Surge Return Intervals, Oh My! A Sea Level Rise Assessment Case Study from the Pacific Northwest, USA.” Poster Presentation. Ocean Sciences 2014. February 15, 2014, 
Honolulu, HI. http://www.eposters.net/poster/pdos-and-slow-slip-and-storm-surge-returnintervals-oh-my-a-sea-level-rise-assessment-case-study.

Moser, S. C., and J. Ekstrom. 2010. "A Framework to Diagnose Barriers to Climate Change Adaptation." Proceedings of the National Academy of Sciences 107 (51): 22026-22031. doi:10.1073/ pnas.1007887107.

Moss, R. H., A. L. Brenkert, and E. L. Malone. 2001. Vulnerability to Climate Change: A Quantitative Approach. Prepared for the U.S. Department of Energy under Contract DE-AC0676RLO 1830. http://www.globalchange.umd.edu/data/publications/Vulnerability_to_Climate_Change.PDF

Muntaner, C., H. Chung, K. Murphy, and E. Ng. 2012. "Barriers to Knowledge Production, Knowledge Translation, and Urban Health Policy Change: Ideological, Economic, and Political Considerations." Journal of Urban Health : Bulletin of the New York Academy of Medicine 89 (6): 915-24. doi:10.1007/s11524-012-9699-1.

National Research Council. 2010a. America's Climate Choices: Adapting to the Impacts of Climate Change. Washington, DC: National Research Council.

- 2010b. America's Climate Choices: Advancing the Science of Climate Change. Washington, DC: National Research Council.

Ribot, J. 2011. "Vulnerability before Adaptation: Toward Transformative Climate Action.” Global Environmental Change 21 (4): 1160-1162. doi:10.1016/j.gloenvcha.2011.07.008.

Tompkins, E. L., and H. Eakin. 2012. "Managing Private and Public Adaptation to Climate Change." Global Environmental Change 22 (1): 3-11. doi:10.1016/j.gloenvcha.2011.09.010.

Waters, M., T. Stafford, H. McDonald, C. Gustafson, M. Rasmussen, E. Cappellini, J. Olsen, D. Szklarczyk, L. Jensen, M. Gilbert, and E. Willerslev. 2011. "Pre-Clovis Mastodon Hunting 13,800 Years Ago at the Manis Site, Washington." Science 334 (6054): 351-353.

Wiener, J. 2007. “Think Globally, Act Globally: The Limits of Local Climate Policies.” 155: 19611979. 